\title{
Carol Young
}

\author{
Juan Gustavo Cobo Borda (Colombia)
}

coborda@gmail.com

\section{Resumen}

En este artículo, Juan Gustavo Cobo Borda se acerca a la obra de la artista uruguaya radicada en Colombia, Carol Young. Cobo encuentra en sus delgadas piezas de cerámica reflexiones sobre la naturaleza del papel, y en sus tablillas e instrumentos, un hallazgo arqueológico de origen mítico. En sus instalaciones, Young expone artefactos de cerámica en una especie de exposición sobre la clasificación y el registro de la memoria.

Palabras clave: cerámica, instalación, escultura, papel, historia, memoria, mito.

\section{Abstract}

In this article, Juan Gustavo Cobo Borda reflects on the work of the Uruguayan artist based in Colombia, Carol Young. Cobo finds within her pottery art reflections about the nature of paper and in her instruments, an archeological finding of mythical origin. In her installations, Young displays pottery objects in a sort of exhibition regarding the classification and record of memory.

Keywords: Pottery, facilities, sculpture, paper, history, memory, myth. 
- Carol Young - Juan Gustavo Cobo Borda

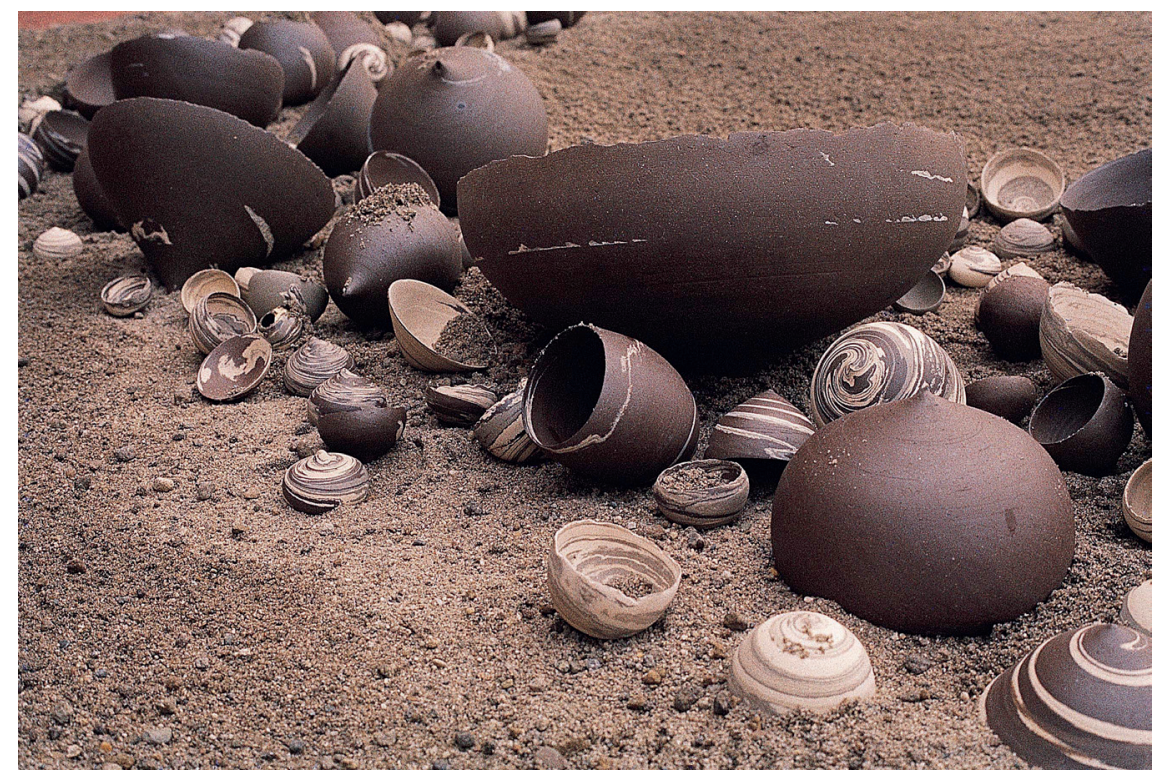

Juegos

Cerámica

Aproximadamente

250 elementos

1992 
La cerámica, en manos de Carol Young, se aplanó y se extendió, como tablilla o pergamino. Como blanca superficie que se envuelve a sí misma cual un papiro o resto arqueológico de una biblioteca horadada por el tiempo. Su labor tiene mucho de fragmento rescatado (punzones o agujas), pero también plantean un retorno al origen, cuando nada se ha dicho. Cuando solo los caracoles, en la playa, nos incitan a descifrar su alfabeto de líneas y círculos. De contrastes de color. Pues ella quiere clasificar, guardar y coleccionar esos folios, esos cuadernillos de libros imaginarios que ubica en un ambiente de museo, biblioteca o estudio. Vastas mesas para desplegarlos como mapas o compactos estantes para almacenarlos y ver sus lomos.

Aquí la memoria ejerce su arte, pues el olvido los escribe. Borra toda mancha y restituye el vacío. Ese nuevo comienzo de una búsqueda. Allí donde hay una plenitud de la nada. Cuenco que llena el agua de lluvia o mente que se abre al contemplar la música de las estrellas, en la oscuridad propicia de las instalaciones. La luz emana, como una imprenta que ha apagado sus máquinas, de los pliegos que ondulan hasta el infinito. Animada por un referente literario o coherente con una trayectoria de varios años y notables exposiciones, los residuos descartados integran nuevas superficies: esas hojillas recortadas que tienen algo filoso e hiriente pues protegen un secreto. Preservan, en sus juegos de luz y sombra, los enigmas indescifrados. Tacto, huellas, asperezas y tersuras. Arte milenario de mujeres que amasaron barro desde Egipto y Babilonia para ofrenda religiosa o utensilio doméstico. No es de extrañar que en nuestros días Anselm Kiefer retome la Biblia y elabore inmensas vasijas 
que serán rotas para conmemorar la destrucción del Templo. También Carol Young apela a los vínculos perdidos para restituirnos la armonía. El diálogo táctil y visual con esos archivos de nuestra identidad perdida o aun no configurada. En su refugio en La Calera, invoca lo ancestral mítico para darle mayor energía a su indagación contemporánea, cerca de los hornos que comunican con el fuego primordial.

Desde las tabletas de arcilla, donde bien puede decirse se consignaron los orígenes de la civilización, hasta estas piezas, tantos siglos después, que surgen poéticamente de los cuatro elementos que Gaston Bachelard entrelazó con tanta intuición y tanta profundidad, Carol Young pasa del agua a la tierra, en el intento inherente a todo artista de recobrar la infancia y ordenar el archivo de sus vivencias y exilios. De sus homenajes funerarios, y de la abigarrada superposición con que despliega esas pequeñas láminas, que en algún momento nos permiten evocar secuencias musicales o el afán imposible de ordenar eso que son solo los restos de una historia material que puede ser tan milenaria como actual. Tan íntimamente suya como abierta a la mirada de quien la contempla o la palpa. Esa cerámica habla y conmueve. Dice más de lo que podemos articular, porque es una voz que atraviesa la historia y se sustenta en el juego blanco de la búsqueda llevada al límite. Al estar rotas o agrupadas en una taxonomía aún más arbitraria y propia, se nos tornan más humanas. J.G. Сово BORDA 


\section{Exposiciones individuales seleccionadas}

2015 «Más que la suma de sus Partes» Fundación Flora ars+natura. Bogotá, Colombia.

2013 «Clasificar, contener, guardar, coleccionar» Galería Beatríz Esguerra, Arte. Bogotá, Colombia.

2011 «Memoria y taxonomías del vacío» VI Premio Luís Caballero. Bogotá, Colombia.

2007 «Transformación» Museo de Arte Moderno de Bogotá. Bogotá, Colombia.

2003 Sin título, Galería Beatríz Esquerra Art. Bogotá, Colombia.

2002 Sin título, Galería Diners. Bogotá, Colombia.

1997 Sin título, Galería Diners. Bogotá, Colombia.

1995 Sin título, Centro Colombo Americano, sede norte. Bogotá, Colombia.

1991 Sin título, Centro Colombo Americano, sede norte. Bogotá, Colombia.

\section{Exposiciones colectivas seleccionadas}

2015 «Waterweavers» Centro Cultural Conde Duque. Madrid, España. «Waterweavers» Museo de las Américas. Washington D.C, Estados Unidos.

2014 «Waterweavers» Bard Graduate Center Gallery. New York, Estados Unidos.

2006 «Agora de Fuego» Museo de Arte, Banco de la República. Bogotá, Colombia.

XIX Salón del Fuego, Gilberto Alzate Avendaño. Bogotá, Colombia.

2004 XVIII Salón del Fuego, Gilberto Alzate Avendaño. Bogotá, Colombia.

2002 XVII Salón del Fuego, Gilberto Alzate Avendaño. Bogotá, Colombia «Artistas Inmigrantes» Galería Mundo. Bogotá, Colombia.

2001 «World Ceramic Exposition 2001» Ichon, Corea. 
«FIA»IX Edición Feria Iberoamericana de Arte. Caracas, Venezuela. Sin título, Museo de Arte Moderno de Bucaramanga. Colombia. 1999 Primeros premios Salones Nacionales 1940-1998. Museo de Arte Moderno de Bogotá. Bogotá, Colombia.

1998 Centro Venezolano de Cultura de Bogotá. Colombia. «Tierra Común» Galería C.A.F. Caracas, Venezuela.

1995 «II Bienal Barro de América» Núcleo I Museo de Arte Contemporáneo de Caracas Sofía Imber. Caracas, Venezuela. «II Bienal Barro de América» Núcleo II Museo de Arte Contemporáneo de Caracas Sofía Imber. Caracas, Venezuela. «Salón de las Artes del Fuego» Fundación Gilberto Alzate Avendaño. Bogotá, Colombia.

1994 XXXV Salón Nacional de Artistas, Corferias. Bogotá, Colombia.

1993 VI Salón Nacional de Artistas, Zona 4 - Corferias. Bogotá, Colombia.

1992 «Barro de América» Museo de Arte Contemporáneo de Caracas Sofía Imber. Caracas, Venezuela. 1990.

XXXIII Salón Nacional de Artistas, Corferias. Bogotá, Colombia.

\section{Distinciones}

2004 II Premio «XVIII Salón del Fuego» Fundación Gilberto Alzate Avendaño. Bogotá, Colombia.

2001 Mención de Honor «I Bienal Internaciona CEBIKO» Ichon, Corea.

1998 Seleccionada para participar en el portafolio AGPA «Cartón de Colombia» con obra gráfica.

Premio adquisición «Orton Cone Box Show» Kansas City, USA.

1995 Primer premio «Salón de las Artes del Fuego»Fundación Gilberto Alzate Avendaño. Bogotá, Colombia.

Mención espacial. Muestra de creación cerámica «para la mesa servida» Museo de Arte Moderno de Medellín, Colombia.

1991 Primer premio. Muestra de creación cerámica «para la mesa servida» Museo de Arte Moderno de Medellín. 